\title{
Attachment of HeLa cells during early G1 phase
}

\author{
Maarten J. A. Moes · Jose J. Bijvelt • \\ Johannes Boonstra
}

Accepted: 26 July 2011 / Published online: 11 August 2011

(C) The Author(s) 2011. This article is published with open access at Springerlink.com

\begin{abstract}
Both growth factor directed and integrin dependent signal transduction were shown to take place directly after completion of mitosis. The local activation of these signal transduction cascades was investigated in early G1 cells. Interestingly, various key signal transduction proteins were found in blebs at the cell membrane within $30 \mathrm{~min}$ after mitosis. These membrane blebs appeared in round, mitoticlike cells and disappeared rapidly during spreading of the cells in G1 phase. In addition to tyrosine-phosphorylated proteins, the blebs contained also phosphorylated FAK and phosphorylated MAP kinase. The formation of membrane blebs in round, mitotic cells before cell spreading is not specific for mitotic cells, because similar features were observed in trypsinized cells. Just before cell spreading also these cells exhibited membrane blebs containing active signal transduction proteins. Inhibition of signal transduction did not affect membrane bleb formation, suggesting that the membrane blebs were formed independent of signal transduction.
\end{abstract}

Keywords Actin - Membrane blebs · G1 .

Signal transduction - Attachment - Focal adhesion .

$\mathrm{FAK} \cdot \mathrm{CPLA}_{2} \alpha$

$\begin{array}{ll}\text { Abbreviations } \\ \text { FAK } & \text { Focal adhesion kinase } \\ \text { EGF } & \text { Epidermal growth factor } \\ \text { SIC } & \text { Spreading initiation center } \\ \text { cPLA }_{2} & \text { Cytotosolic phospholipase } \mathrm{A}_{2}\end{array}$

M. J. A. Moes · J. J. Bijvelt · J. Boonstra ( $\square)$ Department of Cell Biology, Institute of Biomembranes, Utrecht University, Padualaan 8, 3584 CH Utrecht, The Netherlands

e-mail: J.Boonstra@uu.nl

\section{Introduction}

The transition of mitosis to early G1 phase during cell cycle progression is characterized by dramatic changes in cell morphology. The round mitotic cells attach to the substratum and flatten subsequently to the morphology that is well known from interphase cells. In addition to these morphological changes, also the onset of signal transduction cascades was described in early G1 cells (Hulleman et al. 1999a, b). Integrin dependent as well as growth factor dependent signal transduction become activated within half an hour after completion of mitosis. It has been demonstrated during the on-going cell cycle of Chinese Hamster Ovary $(\mathrm{CHO})$ and neuroblastoma N2A cells that serum induces the activation of the MAP kinase pathway within 15 min after mitosis, and that inhibition of this activation causes an inhibition of cell cycle progression (Hulleman et al. 1999a). Similarly, prevention of cell attachment also resulted in cell cycle arrest (Hulleman et al. 1999b).

In addition to growth factors and adhesion, organization of the actin cytoskeleton is also implicated in G1 phase progression since disruption of actin architecture with pharmacological agents leads to G1 arrest in a variety of cell types (Bohmer et al. 1996; Bottazzi et al. 2001; Fasshauer et al. 1998; Huang et al. 1998, Huang and Ingber 2002; Iwig et al. 1995; Lohez et al. 2003; Maness and Walsh 1982; Ohta et al. 1985; Reshetnikova et al. 2000; Takasuka et al. 1987; Tsakiridis et al. 1998). In this respect it is of interest that the actin cytoskeleton has been demonstrated to play an essential role in signal transduction (Boonstra and Moes 2005; Heng and Koh 2010). The first indications for the relationship between actin and signal transduction were obtained by studies on the effects of growth factors on cell morphology. For example, addition of EGF caused the formation of membrane ruffles within 
minutes after addition of the growth factor (Diakonova et al. 1995). It was demonstrated that exposure of cells to EGF caused a rapid actin polymerization. The formation of membrane ruffles and the translocation of several of the downstream signaling molecules to these newly formed membrane ruffles suggested the formation of signaling complexes at the plasma membrane in the membrane ruffles (Diakonova et al. 1995; Payrastre et al. 1991). Interestingly, treatment of the cells with F-actin disrupting agents like cytochalasin caused a severe reduction in growth factor induced signaling (Margadant et al. 2007), demonstrating the mutual interaction between signaling cascades and the actin microfilaments. Furthermore, a wide variety of signaling proteins, amongst them the epidermal growth factor receptor, were demonstrated to associate directly to actin (den Hartigh et al. 1992; Diakonova et al. 1995; Payrastre et al. 1991). These observations suggest strongly that the drastic changes in the actin microfilament system during the transition from $M$ to early G1 phase may be related to the onset of growth factor and integrin mediated signal transduction.

To establish the possible role of actin in signal transduction in the early G1 phase of the cell cycle, we have studied the localization of these signal transduction molecules and of F-actin using immunofluorescence microscopy in the early G1 phase of the ongoing cell cycle. It was shown that various key signal transduction proteins, such as phosphorylated FAK and MAPK, were present in blebs of the cell membrane in cells in early G1 phase. Cells that progressed further into G1 phase and that were spread further, exhibit small focal adhesions and less membrane blebs. Both the presence of phosphorylated FAK within these blebs and the temporal presence of the membrane blebs during the spreading of cells directly after mitosis, suggest a role in facilitating attachment. Interestingly, inhibition of the FAK-mediated or MAPK-mediated signal transduction by specific inhibitors did not influence the formation of the membrane blebs. This suggests that membrane bleb formation is independent from signal transduction. Membrane blebs may facilitate plasma membrane enlargement and efficient integrin and growthfactor induced signalling that is required during early G1 phase.

\section{Materials and methods}

Cell culture synchronization and trypsinization

HeLa cells and $\mathrm{CHO}$ cells were cultured in $\mathrm{CO}_{2}$ independent Dulbecco's modified Eagle's medium (DMEM) containing 25 mM HEPES (Gibco/Invitrogen, Paisley, UK), supplemented with $7.5 \%$ fetal calf serum (Gibco/Invitrogen,
Paisley, UK). Cell cultures were synchronized by mitotic shake off (Boonstra et al. 1981). After shake off, mitotic cells were plated on glass coverslips and allowed to progress in $\mathrm{G} 1$ phase for various time intervals before chemical fixation.

Cells were trypsinized according general procedures and allowed to spread for 30 or $60 \mathrm{~min}$ after replating. Subsequently cells were chemically fixed and labelled for proteins that are phosphorylated on tyrosine residues (PY100) and F-actin as described under Fluorescence microscopy. Cells were trypsinized and plated on fibronectin and polyL-lysine, respectively, in the absence or presence of serum for 10 or $20 \mathrm{~min}$. Subsequently the fraction of the initial plated cells was calculated that displayed a spread or round morphology and the fraction of initial plated cells that contained membrane blebs. Cells were counted before replating and non-attached cells are not included in the calculation because the cells were allowed to attach for only 10 or $20 \mathrm{~min}$. The presented data of the trypsinization assay represent two individual experiments.

\section{Fluorescence microscopy}

Cells were fixed in $3.7 \%$ (w/v) formaldehyde in PBS, washed with PBS and permeabilized for $5 \mathrm{~min}$ in PBS containing $0.2 \%$ Triton X-100. After washing with PBS, cells were incubated with $50 \mathrm{mM}$ glycine in PBS for 10 minutes. Subsequently samples were washed twice with PBS containing $0.2 \%$ gelatin and incubated with the primary antibody diluted in PBS containing $0.2 \%$ gelatine during $60 \mathrm{~min}$, with the exception of the anti-cPLA $\mathrm{A}_{2} \alpha$ antibody that was incubated overnight. After several washings with PBS containing $0.2 \%$ gelatin, cells were incubated with a secondary antibody and TRITC-conjugated phalloidin diluted in PBS containing $0.2 \%$ gelatine and washed again with PBS containing $0.2 \%$ gelatin. Finally, cells were mounted in $(2.5 \% \mathrm{w} / \mathrm{v})$ mowiol $4-88$ (Hoechst, Frankfurt, Germany)-DAPCO (Sigma-Aldrich St. Louis, USA). All individual experiments were carried out at least three times. Experiments with double labelling were also performed with single labels, among others to control for bleedthrough of the fluorophores. Controls with incubations of solitary secondary antibodies were carried out routinely with identical settings of the microscope.

Acquisition of immunofluorescence images

Images were acquired with a Zeiss confocal laser scanning microscope (CLSM) (Pascal 510) fitted with Zeiss objective lenses $(40 \times$ N.A. 1.3 and $63 \times$ N.A. 1.4). Images in Figs. 1, 2, 3, 4, 6, 7, 8 and 9 represent single optical slices along the $z$-axis. The optical section thickness was kept identical for both the red and the green channels. Images in 
Fig. 5 represent projections along the $z$-axis. The lay-out of the pictures was created with Adobe Photoshop ${ }^{\circledR}$ 8.0.

\section{Antibodies}

The monoclonal antibody raised against PY100 was purchased from Cell Signalling, the antibody recognizing phospho-FAK ${ }^{397}$ was purchased from Biosource/Invitrogen (Paisley, UK), the antibody raised against $\mathrm{cPLA}_{2} \alpha$ (sc-1724; concentration used: $4 \mu \mathrm{g} / \mathrm{ml}$ ) and phosphocPLA $_{2} \alpha$ (Ser 505) (sc-34391; concentration used: $1 \mu \mathrm{g} / \mathrm{ml}$ ) were purchased from Santa Cruz, the antibody raised against MAPK (concentration used: $2 \mu \mathrm{g} / \mathrm{ml}$ ) was from Upstate and the phopho-p44/42 MAPK antibody was purchased from Cell Signaling. Secondary antibodies (GAR Alexa 488, GAM Alexa 488 and DAG Alexa 488; all used at concentrations of $1 \mu \mathrm{g} / \mathrm{ml}$ ) were purchased from Molecular Probes/ Invitrogen (Paisley, UK), tetramethylrhodamine-5-(and-6)isothiocyanate (TRITC) conjugated Phalloidin (concentration used: $67 \mathrm{ng} / \mathrm{ml}$ ) was purchased from Sigma-Aldrich (St. Louis, USA).

\section{Results}

Signal transduction is induced at the cell membrane directly after mitosis

In order to establish the localization of signalling proteins during the transition from mitosis to G1 phase, mitotic cells synchronized by shake-off, were labelled with antibodies directed against tyrosine phosphorylated proteins and F-actin as described under "Materials and methods". Both growth factor- and integrin-directed signalling activate signal transduction cascades that involve tyrosine phosphorylation of various proteins and as such this parameter is well suited to establish signal transduction. Synchronized mitotic cells were cultured and allowed to progress into G1 phase for $30 \mathrm{~min}$ before chemical fixation as indicated. Other samples were allowed to progress into G1 phase for 1, 2, 3, 4, 5 and $6 \mathrm{~h}$ before chemical fixation. Subsequently cells were labelled with an antibody directed against proteins that are phosphorylated on tyrosine residues (PY100). In the same samples, cells were also labelled for F-actin. Immunofluorescence microscopy revealed the local presence of phosphorylated proteins at the cell membrane $30 \mathrm{~min}$ after replating (Fig. 1a). These local concentrated spots with phosphorylated proteins are encased in a sheath of F-actin (Fig 1b) that seems to induce blebs of the cell membrane. Other cells in the same sample were spread a bit more (Fig. 1d-f). These cells showed a broader region of F-actin at the basal side where the cells grow outwards (Fig. 1e). The spreading of cells was further illustrated by the presence of stress fibers (Fig. 1e). Here, the individual blebs were no longer recognizable. Interestingly, these cells exhibit small focal adhesions both detected with the probe directed against F-actin (Fig. 1e) and the antibody directed against phosphotyrosine proteins (Fig. 1d). The tyrosine phosphorylated proteins and F-actin clearly localize at the same sites, as shown by the merged images (Fig. 1c, f). The presence of tyrosine phophorylated proteins indicates active signal transduction localized in spots at the cell membrane within 30 min after mitosis.
Fig. 1 Localization of tyrosine phosphorylated proteins and F-actin in early G1 phase HeLa cells. HeLa cells were chemically fixed 30 min after mitotic shake off and stained for PY100 (green) and F-actin (red) as described in "Materials and methods". The upper panel $(\mathbf{a}-\mathbf{c})$ represents the initial stage after mitosis. Cells exhibit blebs of the cell membrane that contain F-actin and are enriched with proteins that are phosphorylated at tyrosine residues. Cells that are spread further exhibit small focal adhesions and thin actin stress fibers (d-f). Cells that show small focal adhesions contain no blebs of the cell membrane. Bar represents $10 \mu \mathrm{m}$
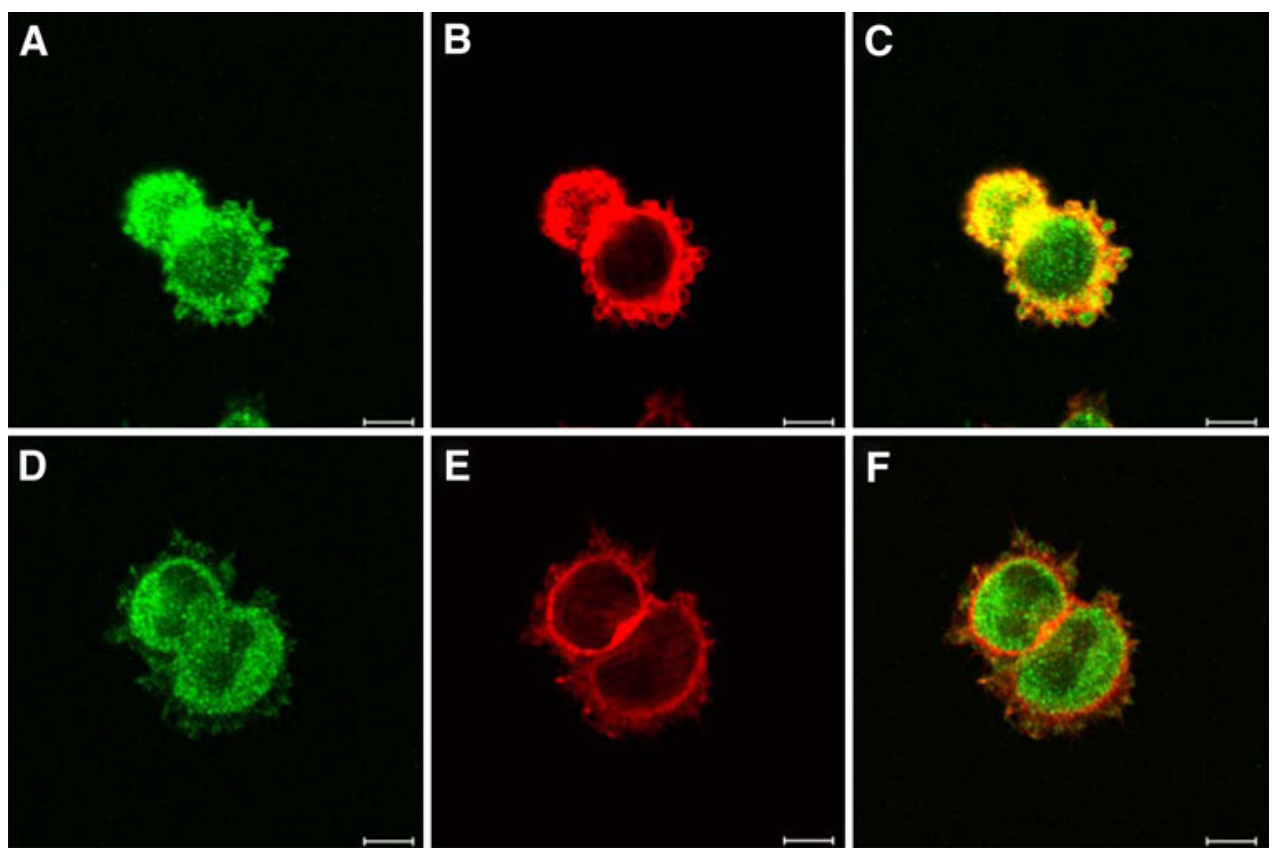
Fig. 2 Localization of tyrosine phosphorylated proteins and F-actin in G1 phase of HeLa cells. HeLa cells were

synchronized by mitotic shakeoff and replated for 1, 2, 3, 4, 5 and $6 \mathrm{~h}$, respectively, as

indicated. Labelling of tyrosine phosphorylated proteins [PY100 labelling (green)] is localized throughout the cytoplasm and in focal adhesions. F-actin

[Phalloidin labelling (red)] is present in focal adhesions and stress fibers. Focal adhesions increase both in size and in number $(\mathbf{a}, \mathbf{d}, \mathbf{g}, \mathbf{j}, \mathbf{m}, \mathbf{p})$. During time, the actin stress fibers become more apparent $(\mathbf{b}, \mathbf{e}, \mathbf{h}$, $\mathbf{k}, \mathbf{n}, \mathbf{q})$. Bar represents $10 \mu \mathrm{m}$
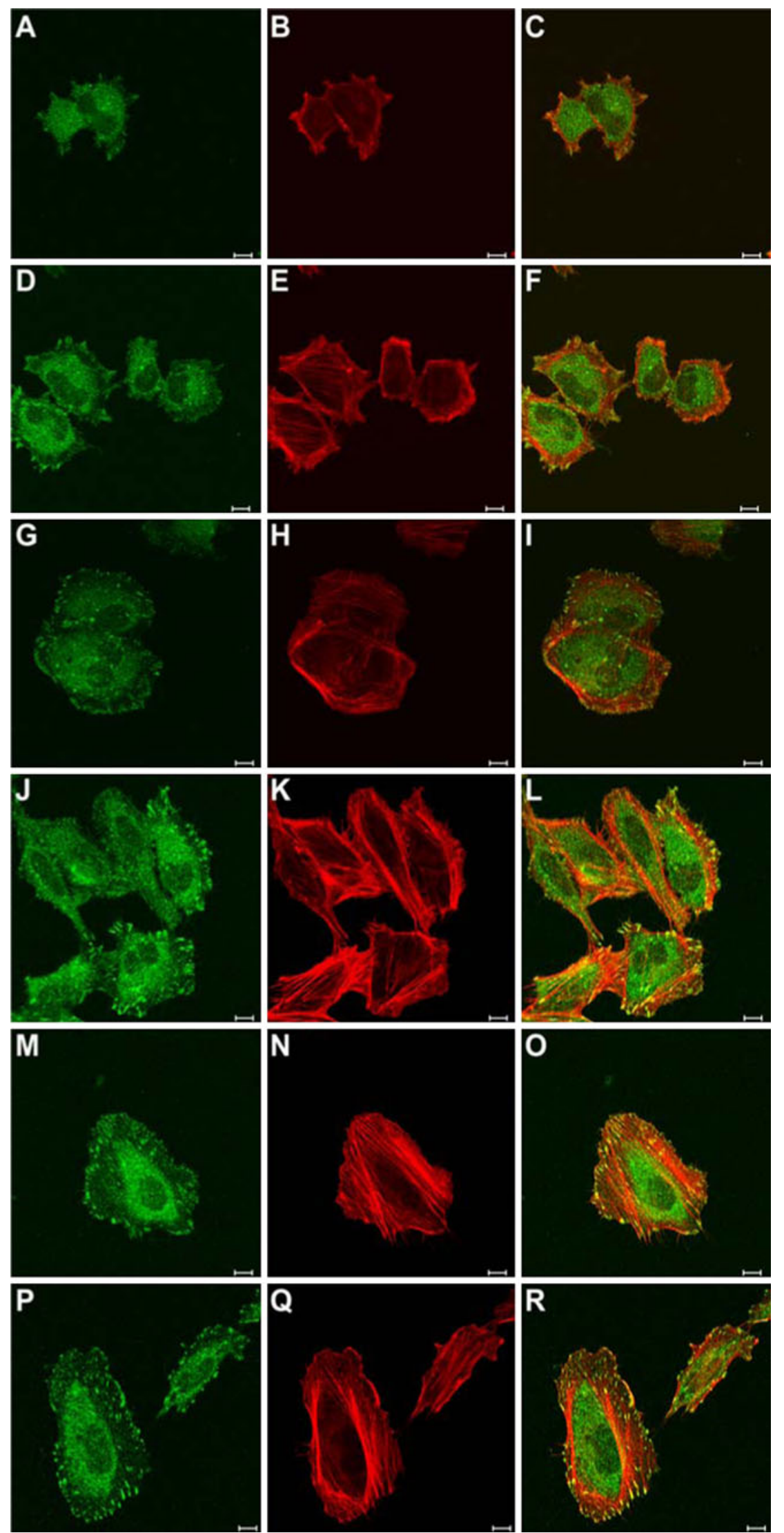
Fig. 3 Localization of phosphorylated FAK during early G1 phase in HeLa cells. a HeLa cells were synchronized by mitotic shake-off and replated for $40 \mathrm{~min}$ followed by chemical fixation as described under "Materials and methods". Phospho-FAK ${ }^{397}$ (green) and F-actin (red) were labeled as described under "Materials and methods". Three optical sections of the same cells are represented: $A$ basal side, $B$ middle part and $C$ apical side. P-FAK ${ }^{397}$ was detected in membrane blebs at the cell surface cells. The blebs contained F-actin, and P-FAK $^{397}$ localized in membrane blebs was surrounded with a coat of F-actin $(\mathbf{a} C, F)$. a $D, E, F$ represents an optical section through the center of the cell that clearly exhibits blebs at the edge of the cell. The blebs of the membrane were present on the whole cell surface, from the basal side (a $A, B, C$ ) to the apical side (a $G, H, I)$. Bar represents $10 \mu \mathrm{m}$.

b Synchronized HeLa cells that were chemically fixed $1 \mathrm{~h}$ after replating were stained for Phospho-FAK ${ }^{397}$ (green) and F-actin (red). Three optical sections of the same cells are represented: $A$ basal side, $B$ middle part and $C$ apical. After $60 \mathrm{~min}$, the number of blebs decreased at the apical side of cells (b $G, H, I$ vs. a $G$, $H, I)$. Optical sections through the center of the cell revealed no blebs of the membrane (b $D, E$, $F$ ) in contrast to

sections $40 \mathrm{~min}$ after mitosis (a $D, E, F)$. However, in the cells that were fixed after $60 \mathrm{~min}$, some blebs were observed that contain P-FAK ${ }^{397}$ at the basal side of cells (b $A, B$, C). Bar represents $10 \mu \mathrm{m}$

\section{a}
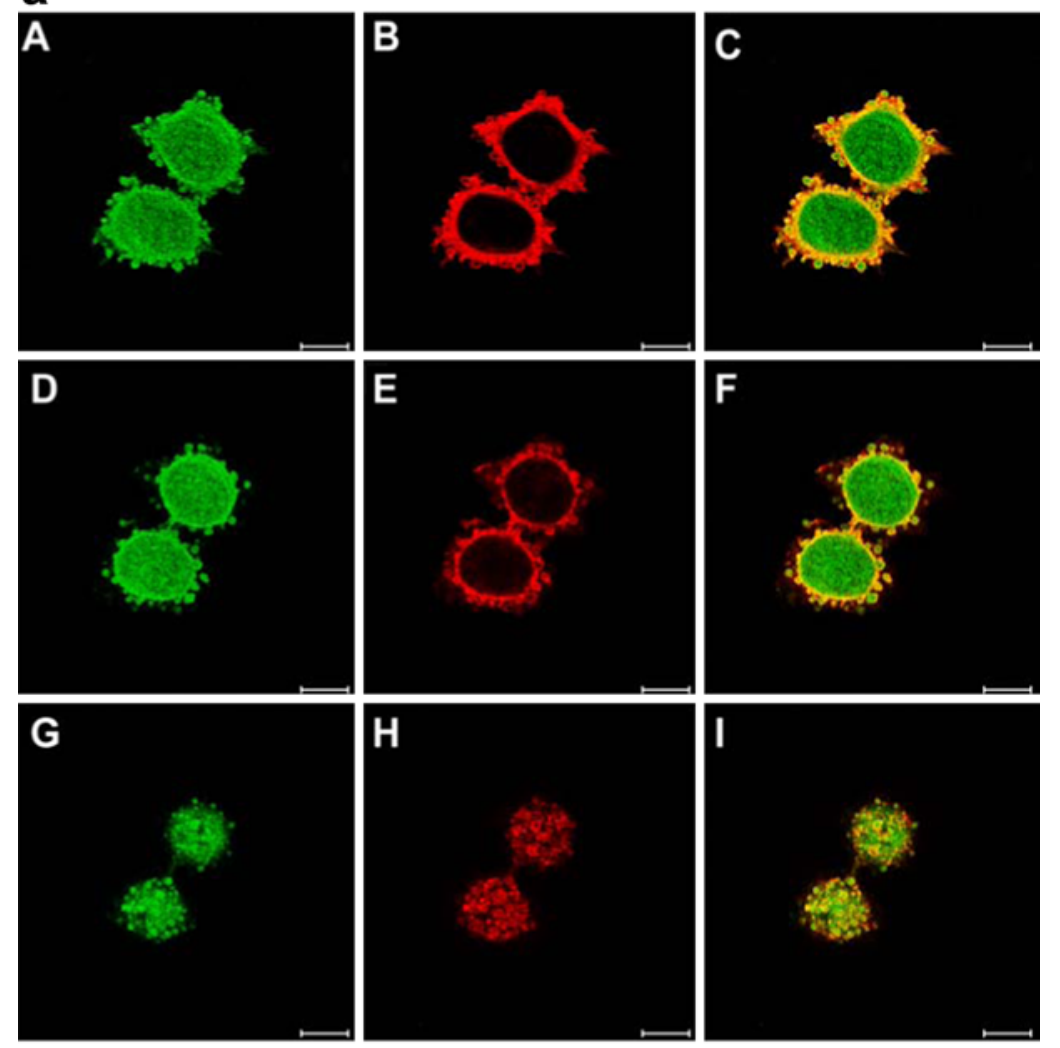

b
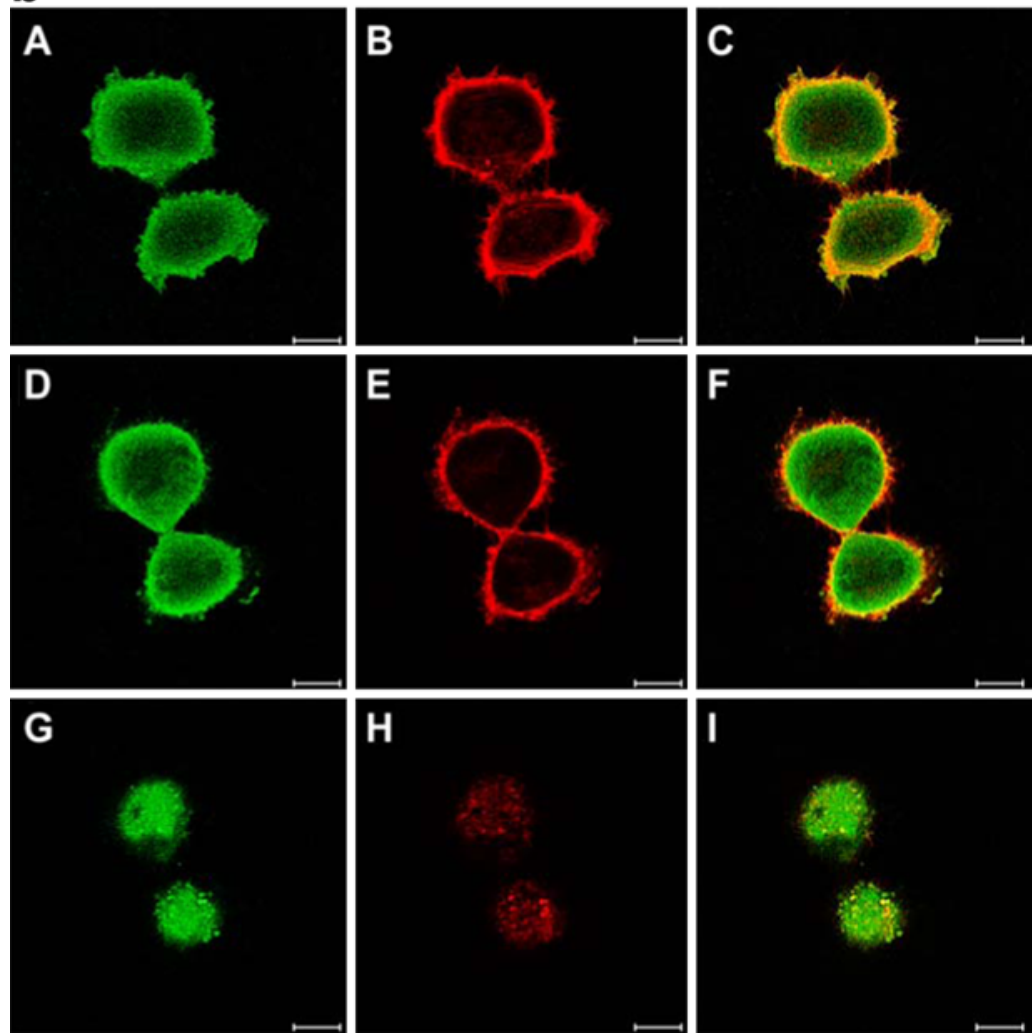
Fig. 4 Localization of MAP kinase and phosphorylated MAP kinase during early G1 phase in HeLa cells. HeLa cells were synchronized, replated and chemically fixed as described under "Material and methods" and Legends of Fig. 3.

Subsequently cells were labelled for MAPK or phosphoMAPK labelling (green) and F-actin labeling (red). MAPkinase (a) and phosphoMAPkinase (d) are localized in blebs of the cell membrane that can be distinguished from the rest of the cell by the packaging in F-actin (b, e). Bar represents $10 \mu \mathrm{m}$
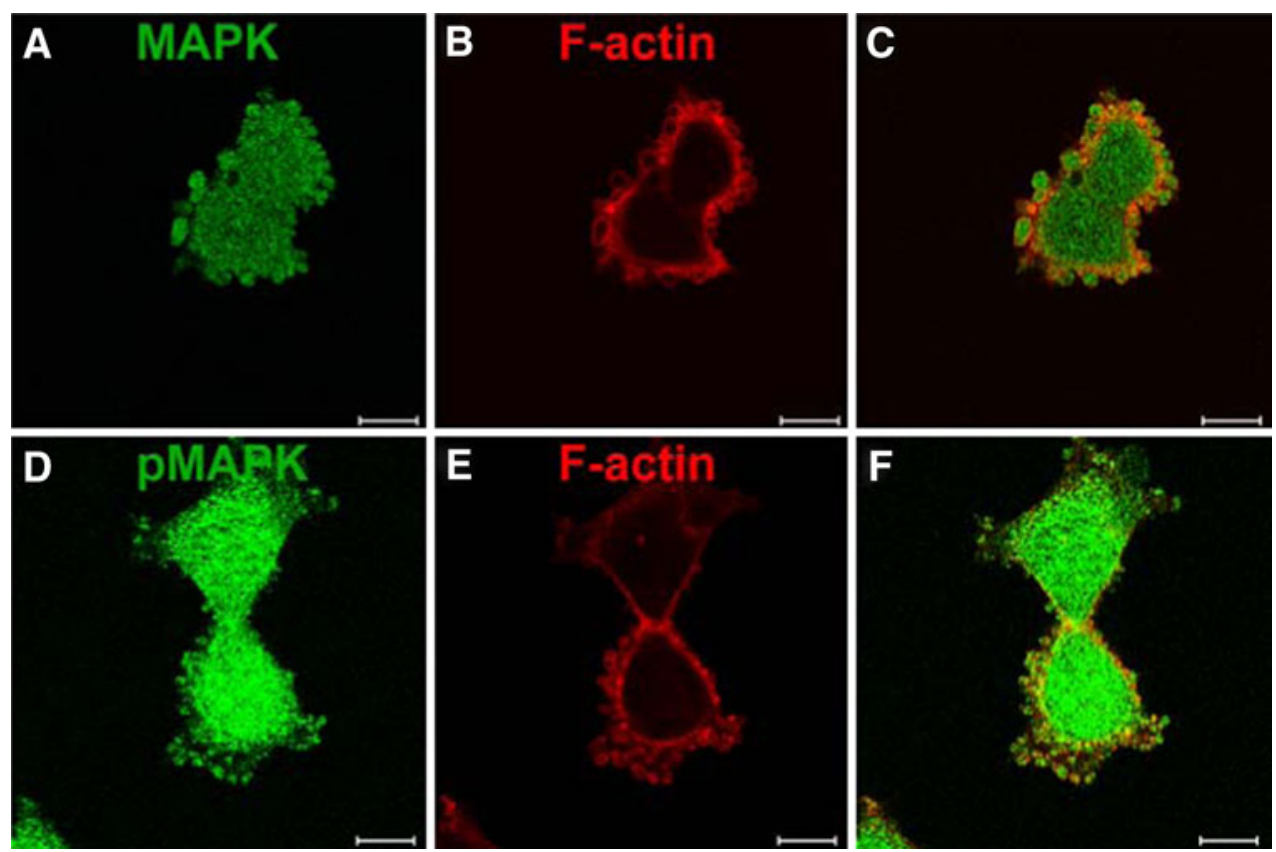
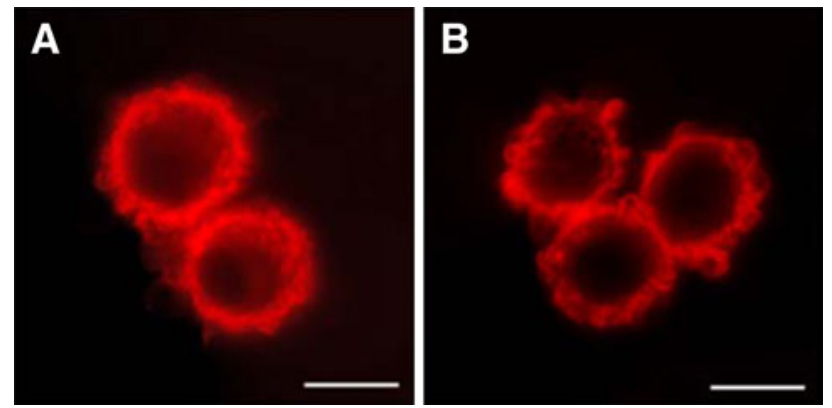

Fig. 5 Blebs of the cell membrane in post-mitotic cells in a random growing cell cultures of $\mathrm{CHO}$ (a) and HeLa cells (b). Blebs of the cell membrane were detected by labelling for F-actin. Bar represents $10 \mu \mathrm{m}$

During progression through the G1 phase, the tyrosine phosphorylated proteins were present at the cell membrane, especially in spots $1 \mathrm{~h}$ after mitosis (Fig. 2a) and onwards in G1 phase (Fig. 2d, g, j, m, p), these spots most likely represent focal adhesions. Stress fibers became clearly visible after $2 \mathrm{~h}$ after mitosis (Fig. 2e). The focal adhesions often are located at the tips of stress fibers, as is known from interphase cells (Badley et al. 1980). Focal adhesions increase both in size and in number (Fig. 2a, d, g, j, m, p). The merged images clearly demonstrate a co-localization of tyrosine phosphorylated proteins and F-actin in the apparent focal adhesions. In addition, a band of F-actin was clearly visible beneath the plasma membrane which did not co-localize with tyrosine phosphorylated proteins (Fig. 2). During progression into the G1 phase, cells occupy increased surface area, illustrating the flattening of cells. Both at the basal side (Fig. 2) and the apical side (data not shown), cells no longer exhibit membrane blebs as was detected with CLSM by making optical sections through the cell. Figures 1 and 2 demonstrate that active signal transduction is localized in spots at the cell membrane, first in blebs of the cell membrane and later in newly formed focal adhesions.

Phosphorylated FAK is present in blebs of the cell membrane

The local presence of tyrosine phosphorylated proteins in the membrane blebs illustrates activated signal transduction and might result both from activation by soluble growth factors and from activation by integrins. The appearance of small focal adhesions suggests the activation of integrin-induced signal transduction. Therefore attachment induced signal transduction was further investigated by measuring the local presence of phosphorylated Focal Adhesion Kinase (FAK), since the phosphorylation has been demonstrated to be prerequisite for activation of this kinase (Schaller 1996, 2010).

Cells were synchronized by mitotic shake-off and subsequently replated for 40 or $60 \mathrm{~min}$ as indicated. After fixation the cells were labelled with an antibody directed against FAK phosphorylated on tyrosine residue 397 $\left(\mathrm{P}-\mathrm{FAK}^{397}\right)$, and with phalloidin to stain F-actin as described under "Materials and methods". The cells were studied using confocal laser scanning microscopy (CLSM). As shown in Fig. 3a, P-FAK ${ }^{397}$ was detected in membrane blebs at the cell surface of these cells, in addition to a cytoplasmic and nuclear localization. The blebs contained F-actin, and from the merged image it was observed that 
P-FAK ${ }^{397}$ localized in membrane blebs was surrounded with a coat of F-actin (Fig. 3a CF). Figure 3a DEF represents an optical section through the center of the cell that clearly exhibits blebs at the edge of the cell. The blebs of the membrane were present on the whole cell surface, from the basal side (Fig. 3a ABC) to the apical side (Fig. 3a GHI).

After $60 \mathrm{~min}$, the number of blebs decreased at the apical side of cells (Fig. 3b, GHI vs. Fig. 3a GHI). Optical sections through the center of the cell revealed no blebs of the membrane (Fig. 3b DEF) in contrast to sections $40 \mathrm{~min}$ after mitosis (Fig. 3a DEF). However, in the cells that were fixed after $60 \mathrm{~min}$, some blebs were observed that contain P-FAK $^{397}$ at the basal side of cells (Fig. 3b ABC). Therefore, P-FAK ${ }^{397}$ labeling is temporally present in blebs at the cell membrane in post-mitotic cells. Furthermore, membrane blebs, including P-FAK ${ }^{397}$ labelling, that are in contact with the extracellular matrix exist for a longer period of time compared to blebs that are not in contact with the extracellular matrix.

Previously, we have studied integrin-mediated FAK autophosphorylation in lysates of mitotic and post-mitotic cells by western blotting, using the same antibody (Margadant et al. 2007). It was shown that the antibody recognized FAK only in attached cells, that is under conditions that FAK is active and phosphorylated, and not in mitotic cells or cells that were detached from the substratum, in contrast to an antibody that recognized un-phosphorylated FAK (Margadant et al. 2007), indicating antibody specificity. Moreover, labelling with various primary antibodies in combination with the secondary antibodies that were presented in this study resulted in no staining in the blebs of the membrane. For example cells that were labelled with antibodies raised against GM130 (mouse IgG1 antibody) and Lamin B (goat polyclonal IgG antibody) revealed no staining in membrane blebs (data not shown). Therefore, we conclude that specific staining was detected in the membrane blebs.

MAPK and phosphorylated MAPK are present in blebs of the cell membrane

It has been demonstrated that serum induces the phosphorylation of MAP kinase (MAPK) immediately after mitosis during the ongoing cell cycle of $\mathrm{CHO}$ and of neuroblastoma N2A cells (Hulleman et al. 1999a). This activation of MAPK during early G1 was shown to be independent of integrin signalling but to require the presence of serum (Hulleman et al. 1999b). The antibodies used in these and other studies have been demonstrated to be highly specific for phosphorylated MAPK in various cell lines (Hulleman et al. 1999b; Margadant et al. 2007). In synchronized $\mathrm{CHO}$ cells, we demonstrated that the antibody directed against phosphorylated MAPK recognized only $\mathrm{p} 42^{\mathrm{MAPK}}$ and $\mathrm{p} 44^{\mathrm{MAPK}}$ by western blotting and that the amount of phosphorylated MAPK increased significantly upon progression of the cells from M to early G1 phase while the amount of total MAPK did not increase (Hulleman et al. 1999b). Similar results were obtained in HeLa cells (data not shown).

In order to establish the potential role of serum in the appearance of tyrosine phosphorylated proteins in the membrane blebs in early G1 phase (Fig. 1), we have studied the localization of phosphorylated MAPK in early G1 phase cells. HeLa cells were synchronized as described above and after 60 minutes cells were fixed and labelled with an antibody directed against MAPK (Fig. 4a), an antibody directed against phosphorylated MAPK (pMAPK) (Fig. 4d) or phalloidin to stain F-actin (Fig. 4b, e). Both MAPK and pMAPK were detected throughout the cytoplasm and both MAPK (Fig. 4a) and pMAPK (Fig. 4d) were present in blebs of the cell membrane, recognizable by the sheath of F-actin (Fig. 4b, e), as has been observed for tyrosine phosporylated proteins (Fig. 1). So, apparently the phosphorylation of proteins in early G1 phase that is present in membrane blebs that was demonstrated in Fig. 1, is caused by the activation of both growth factor- and integrin-induced signal transduction.

Post-mitotic membrane blebs are present in random growing cell cultures

The studies presented so far have been performed with mitotic cells synchronized by mitotic shake-off. To exclude possible artefacts due to the synchronization method, exponentially growing $\mathrm{HeLa}$ cells were labelled for F-actin. In these cultures, the cells in mitosis are recognized by their morphology, being round versus the flat morphology of spread interphase cells. As shown in Fig. 5, cells immediately after cytokinesis exhibit membrane blebs comparable to the membrane blebs observed in synchronized cells (Figs. 1, 3a, 4). Similar results were obtained in early G1 phase cells in an exponential growing $\mathrm{CHO}$ culture (Fig. 5a). This suggests that the presence of membrane blebs in post-mitotic cells is a general phenomenon and is not induced by the shake off.

Membrane blebs during the spreading of trypsinized HeLa cells

The presence of phosphorylated FAK in membrane blebs during early G1 phase in round cells suggests that the membrane blebs are involved in the attachment during spreading of these cells. This is supported by the observation of the appearance of small focal adhesions simultaneously with the disappearance of membrane blebs 
during the spreading of cells that suggests a role in attachment by creating the focal adhesions in the basal membrane. Alternatively or complementary, the disappearance of membrane blebs during the spreading of round early G1 cells, might deliver the extra membrane that is required due to the increased surface volume ratio that takes place during the spreading of round cells. This implicates that the formation of membrane blebs is related to attaching and spreading of cells, rather than to a specific cell cycle phase, and as such this phenomenon may be expected to occur in trypsinized cells that are allowed to attach and spread regardless the cell cycle phase. Therefore, exponentially growing $\mathrm{HeLa}$ and $\mathrm{CHO}$ cells were trypsinized and subsequently allowed to attach and spread for 30 or $60 \mathrm{~min}$, respectively. The cells were fixed and labelled using an antibody directed against tyrosine phosphorylated proteins and using phalloidin to visualize F-actin. As shown in Fig. 6a A and C $30 \mathrm{~min}$ after replating both $\mathrm{HeLa}$ and $\mathrm{CHO}$ cells exhibit blebs of the cell membrane that were shielded with F-actin and contained proteins that are phosphorylated on tyrosine residues. These blebs were very similar as compared to the blebs that were observed during early G1 in HeLa cells that were described in the previous figures. Similar results were obtained with synchronized CHO cells during early G1 (data not shown). $30 \mathrm{~min}$ later, i.e. $1 \mathrm{~h}$ after replating, cells occupied a larger surface area indicating the spreading of cells and most of the membrane blebs disappeared (Fig. $6 \mathrm{aB}, \mathrm{D}$ ). The fast disappearance of the blebs of the membrane is again comparable with the results obtained with early G1 cells. These observations indeed suggest that membrane blebbing in early G1 phase is related to cell attachment and not specifically to the cell cycle phase.

In order to determine the role of integrin-induced signaling in this process, cells were trypsinized and subsequently incubated on petridishes coated with either fibronectin or poly-L-lysine. We have shown previously that this culture strategy can be used to determine the role of integrins in cell attachment and spreading (Hulleman et al. 1999b). After 10 or $20 \mathrm{~min}$, the cells were fixed and their morphology established by light microscopy. As shown in Fig. 6b, the fraction of cells that is spread increases in time from $31 \%$ after $10 \mathrm{~min}$ to $87 \%$ after 20 min when the cells were plated on fibronectin. In contrast, the fraction that is rounded and exhibits blebs decreases rapidly from $35 \%$ after $10 \mathrm{~min}$ to $7 \%$ after $20 \mathrm{~min}$. In case cells were plated on poly-L-lysine, no spreading of cells was observed. Interestingly, the fraction of cells that exhibits blebs remained constant being $41 \%$ after $10 \mathrm{~min}$ and $39 \%$ after 20 min (Fig. 6b). Culturing the cells on fibronectin in the absence of serum resulted in an increase of spreading from $24 \%$ after $10 \mathrm{~min}$ to $31 \%$ after 20 min. In addition, a decrease was observed in cells containing blebs, from $15 \%$ after 10 min to $6 \%$ after 20 min. These results clearly demonstrate that cell spreading is dependent upon integrin activation. Furthermore, also the formation of membrane blebs occurs on rounded cells under all conditions tested, but the disappearance of the blebs is dependent upon the ability of the cells to spread.

Active cytosolic phospholipase $A_{2} \alpha$ is present in membrane blebs

Recently, we found an interesting new role for $\mathrm{CPLA}_{2} \alpha$ in facilitating local actin and cell membrane dynamics (Moes et al. 2010). Blocking of $\mathrm{CPLA}_{2} \alpha$ activity prevented the formation of PDGF induced local actin and membrane dynamics, such as lamellae and circular ruffles. These structures are induced by actin that locally pushes the membrane outwards. The membrane blebs that are described in this manuscript, are coated with F-actin that might reflect a role for actin in either inducing or maintaining the shape of the membrane blebs. $\mathrm{CPLA}_{2} \alpha$ might facilitate the formation of membrane blebs in a similar way as in the case of PDGF induced actin and membrane dynamics (Moes et al. 2010). Therefore it was investigated if $\mathrm{cPLA}_{2} \alpha$ also plays a role in facilitating the formation of membrane blebs during early G1.

First the local presence of $\mathrm{CPLA}_{2} \alpha$ in the membrane blebs was investigated using an antibody specific for cPLA $_{2} \alpha$ (Grewal et al. 2002; Herbert et al. 2005, 2007). $\mathrm{CPLA}_{2} \alpha$ was localized in the cytoplasm of cells and in the blebs of the membrane (Fig. 7a-c). In later stages, actin had formed a ruffling leading edge where cells expand lateral and less blebs shielded with F-actin were visible (Fig. 7d-f). In these cells, cPLA $2 \alpha$ was present at the ruffling edge of the cells. At this edge, $\mathrm{cPLA}_{2} \alpha$ colocalizes with newly formed F-actin structures. In cells that progressed into the G1 phase for more than $2 \mathrm{~h}$, these sites of co-localization of $\mathrm{cPLA}_{2} \alpha$ and F-actin became less abundant and were most clear at protrusions of cells (Fig. $7 \mathrm{~g}-\mathrm{i}$ ).

Subsequently, the activity of $\mathrm{cPLA}_{2} \alpha$ that was present within the blebs and at the ruffling edge of cells was investigated by using an antibody directed against phosphorylated $\mathrm{cPLA}_{2} \alpha$ (Ser 505). P-cPLA $2 \alpha$ was detected in the cytoplasm and in the nucleus. Interestingly, p-cPLA 2 was localized also in the cell membrane blebs (Fig. 8a $\mathrm{ABC}$ ). Half an hour after replating of mitotic cells, p-cPLA ${ }_{2} \alpha$ was present in membrane blebs both at the basal side and at the apical side of cells (Fig. 8a GHI). In later stages, the blebs of the membrane were absent at the apical side of cells (Fig. 8b GHI) and at the basal side p-cPLA $2 \alpha$ was localized at the ruffling edge of cells (Fig. 8b ABC). The localization of p-cPLA $\mathrm{A}_{2} \alpha$ at the edge of post-mitotic cells corresponds to the observed localization for $\mathrm{CPLA}_{2} \alpha$. 

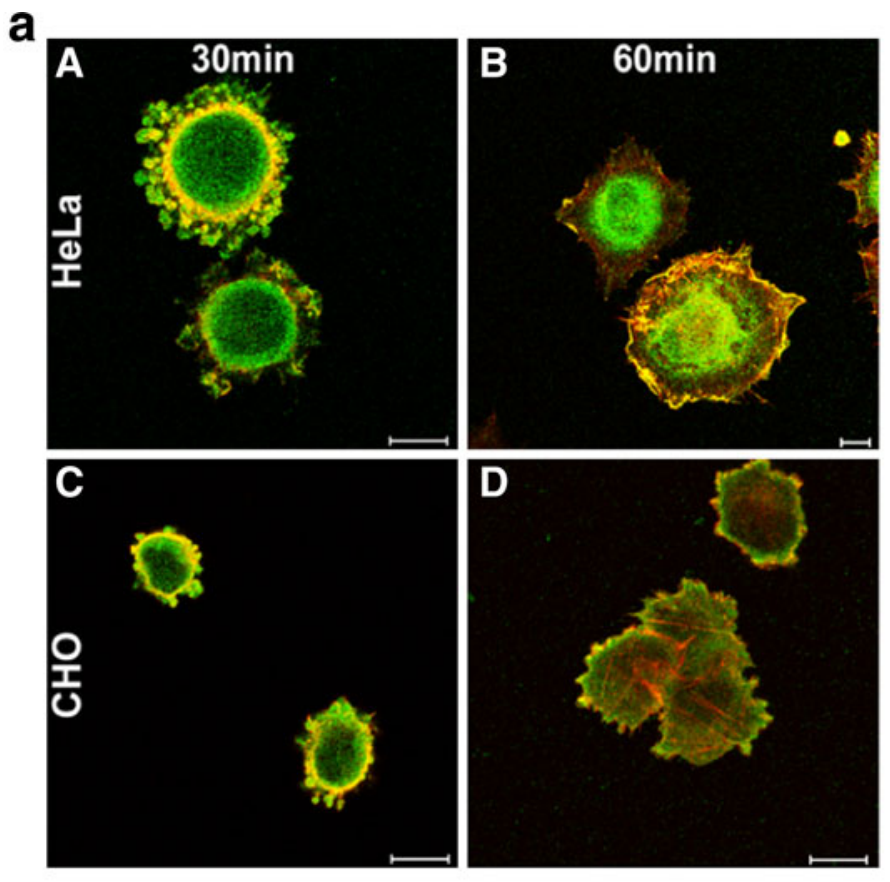

b

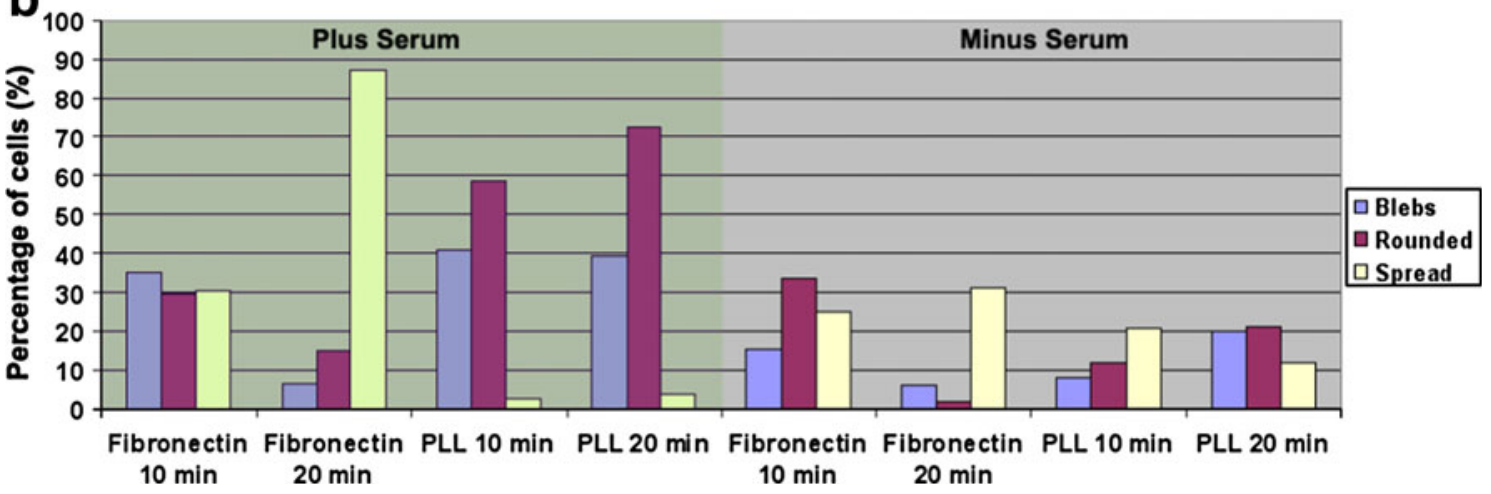

Fig. 6 Spreading of trypsinized HeLa and CHO cells. a Cells were trypsinized according general procedures and allowed to spread for 30 or $60 \mathrm{~min}$ after replating. Subsequently cells were chemically fixed and labelled for PY100 (green) and F-actin (red) as described under "Materials and methods". Bar represents $10 \mu \mathrm{m}$. b Effect of cell substratum on cell spreading and membrane bleb formation in $\mathrm{CHO}$ cells. CHO cells were trypsinized and plated on fibronectin and poly-

Formation of membrane blebs is not related to signal transduction

It is demonstrated above, that round cells (both mitotic and trypsinized) that are allowed to attach and spread to the substratum exhibit membrane blebs and active signal transduction proteins. In order to determine the relationship between these two phenomena, we have inhibited integrininduced signaling by a specific FAK inhibitor, 1,2,4,5-Benzenetetramine tetrahydrochloride, and the MAPK-induced signaling by the specific MEK1 and MEK2 inhibitor PD98059. Subsequently membrane blebs were identified by staining for F-actin similar as for the previous experiments.
L-lysine, respectively, in the absence or presence of serum for 10 or $20 \mathrm{~min}$ as indicated. Subsequently the fraction of the initial plated cells was calculated that had a spread or round morphology and the fraction of initial plated cells that contained membrane blebs. Because the cells were allowed to attach for only 10 or $20 \mathrm{~min}$, non-attached cells are not included in the calculation

The inhibitors caused an inhibition of FAK and MEK1 and MEK2 phosphorylation respectively (data not shown). Under both conditions, membrane blebs were present in the cells as shown for the MEK inhibitor in Fig. 9, indicating that membrane bleb formation is independent of signal transduction.

\section{Discussion}

Here, we describe the morphological changes of HeLa cells that occur during the transition from the M-phase to the early G1 phase. Immediately following the M-phase, 
Fig. 7 Localization of $\mathrm{CPLA}_{2} \alpha$ in G1 phase HeLa cells. HeLa cells were synchronized, replated and chemically fixed as described under "Materials and methods" and Legends of Fig. 3. Subsequently cells were labelled for $\mathrm{cPLA}_{2} \alpha$ (green) and F-actin (red). Chemical fixation was performed $30 \mathrm{~min}(\mathbf{a}-\mathbf{c})$, $1 \mathrm{~h}(\mathbf{d}-\mathbf{f})$, and $4 \mathrm{~h}(\mathbf{g}-\mathbf{i})$ after replating of mitotic cells. Bar represents $10 \mu \mathrm{m}$
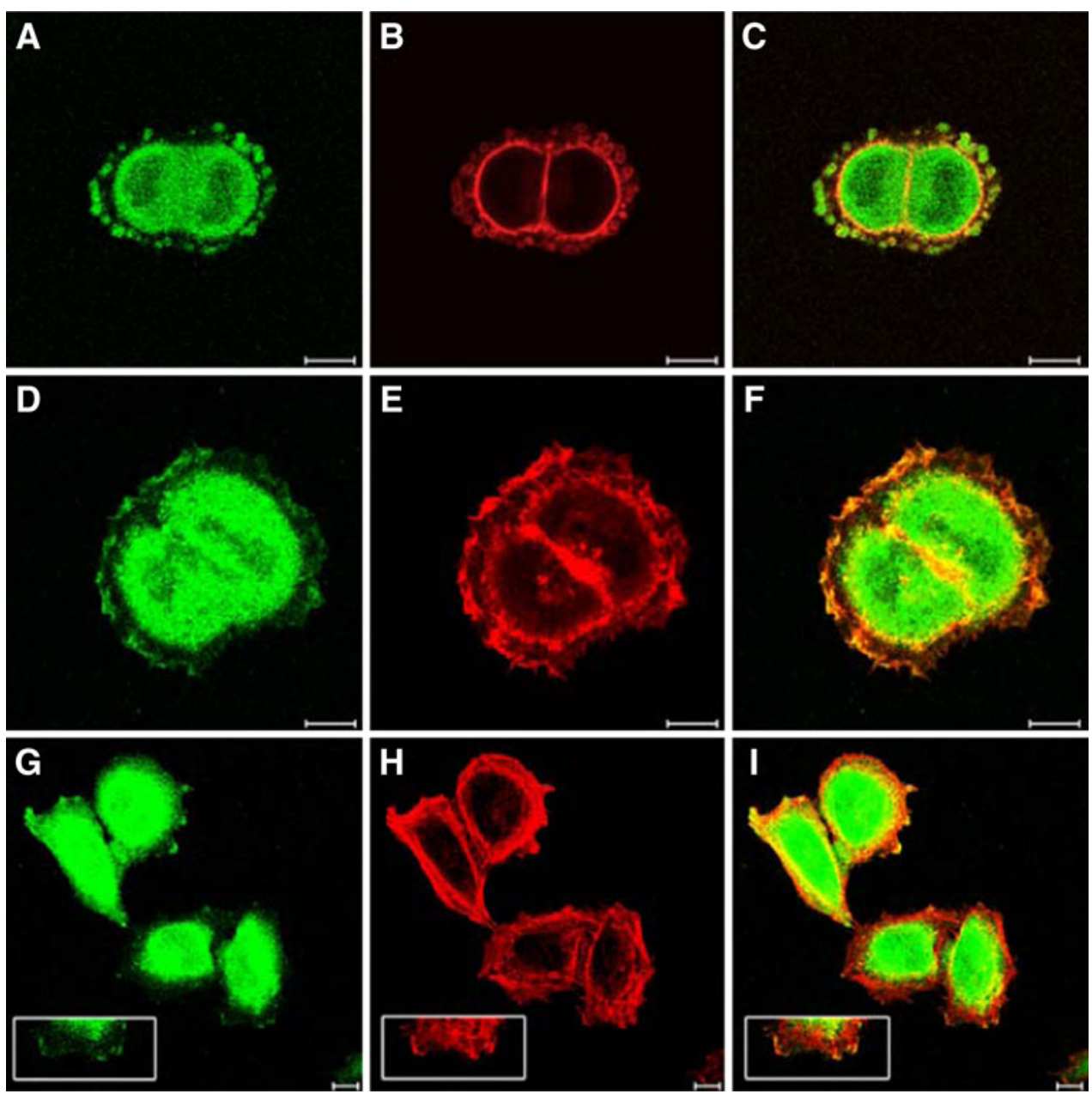

before cell spreading, the cells exhibit numerous blebs at their cell surface. These blebs are shielded with F-actin and it is tempting to suggest that actin polymerization is responsible for the bleb formation as has been demonstrated for other membrane remodelling features as growth factor-induced membrane ruffles and leading edges (Moes et al. 2010). Of particular interest are the observations that the membrane blebs contained tyrosine phosphorylated proteins, but were devoid of lamin B and GM130, a Golgi specific protein (data not shown), suggesting that these blebs exhibit high levels of signal transduction activity. These observations are in line with previously published observations that both growth factor-induced and integrininduced signal transduction cascades are induced within 30 min after M-phase (Hulleman et al. 1999a; Margadant et al. 2007). Furthermore, it has been demonstrated that membrane extrusions, such as membrane ruffles are enriched in signal transduction proteins (Diakonova et al. 1995). Analysis of the presence of both pFAK and of pMAPK indicates the activity of integrin- and of growth factor-induced signaling in these blebs. Similar blebs were also observed if exponentially growing cells were trypsinized and subsequently allowed to adhere and spread. Together these observations suggest that the bleb formation represents a feature related to cell spreading, and apparently not specifically to the M to G1 phase transition.

The observation that small focal adhesions appear directly after the disappearance of the membrane blebs suggests a role in focal adhesion formation and attachment. At the same time that the focal adhesions appear, half an hour after mitosis, thin actin stress fibers appear. The actin stress fibers increase in size during time. Actin has a role in attachment that is demonstrated by the presence of focal adhesions at the tips of actin stress fibers in asynchronously growing cell cultures. However, during mitosis cells are rounded and are less attached to their substratum. After mitosis, cells reattach and flatten during early G1. The observed changes in both the actin cytoskeleton and focal adhesions facilitate the spreading of post-mitotic cells. The blebs of the membrane that were detected before the appearance of small focal adhesions may act as local signalling centers to facilitate the formation of new focal adhesions, similar as described (de Hoog et al. 2004). The temporally existence of Spreading Initiation Centers (SICs) 
Fig. 8 Localization of phospho-cPLA $2 \alpha$ in G1 phase HeLa cells. HeLa cells were synchronized, replated and chemically fixed as described under "Materials and methods" and Legends of Fig. 3.

Subsequently cells were labelled for phospho-cPLA ${ }_{2} \alpha$ (green) and F-actin (red). a 30 min after replating, blebs of the cell membrane containing labelling for phospho-cPLA $\mathrm{A}_{2} \alpha$ are localized at the basal side $(A, B, C)$ as well as at the apical side of cells $(G, H, I)$. b $2 \mathrm{~h}$ after replating, cells exhibit no blebs of the cell membrane at the apical side of cells

$(G, H, I)$ and blebs have increased in size or fused together at the basal side of cells $(A, B, C)$. Bar represents $10 \mu \mathrm{m}$

\section{a}
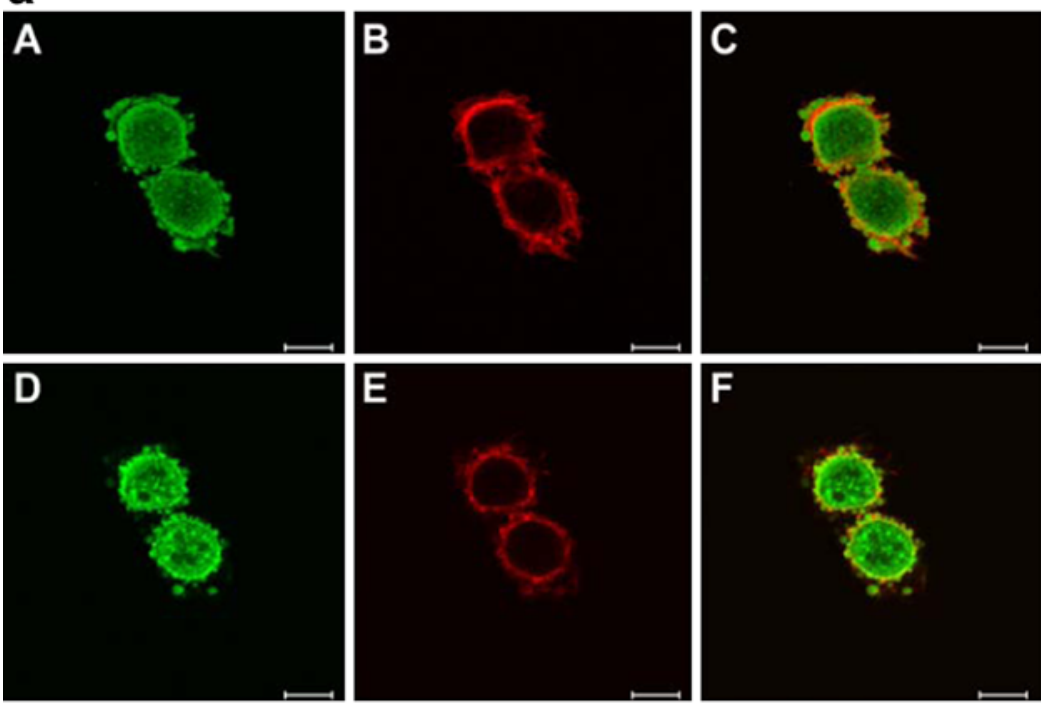

E
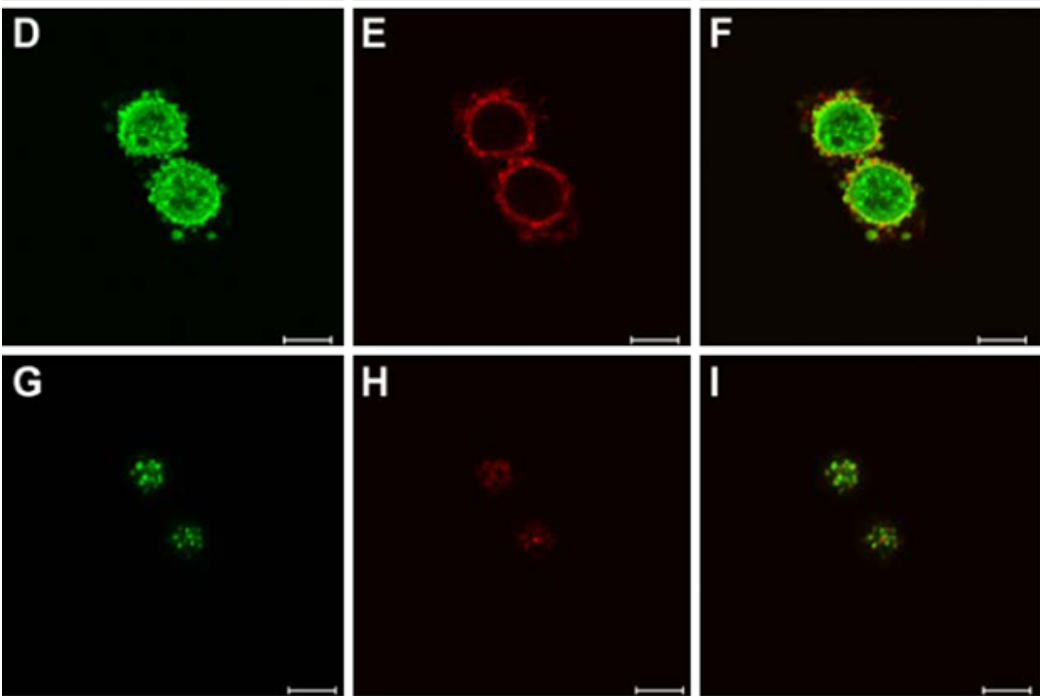

b

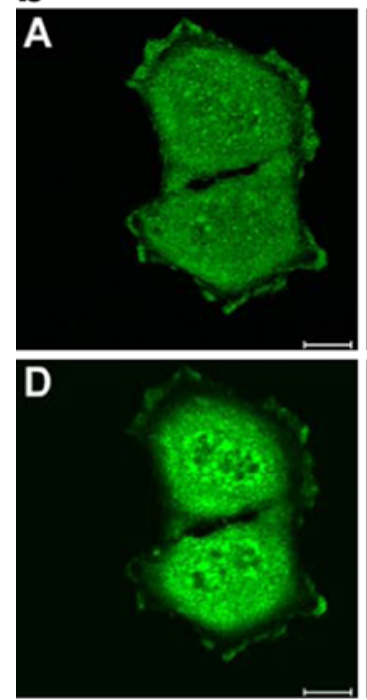

B
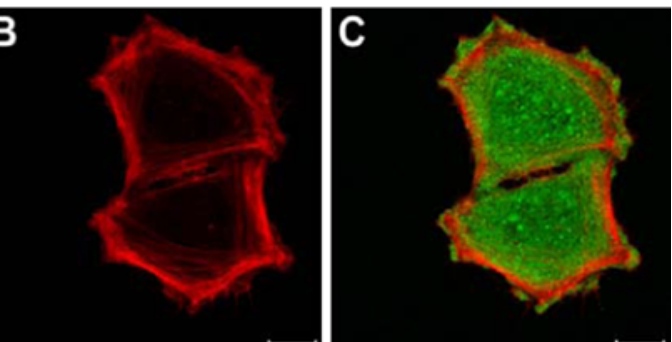

E

$F$
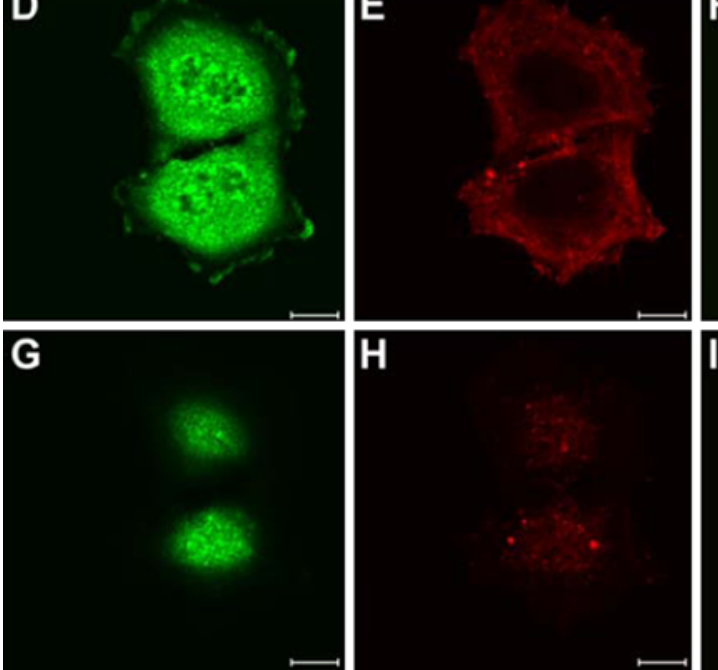

H

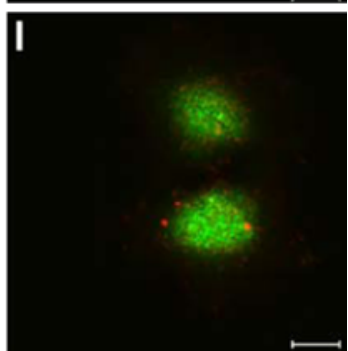



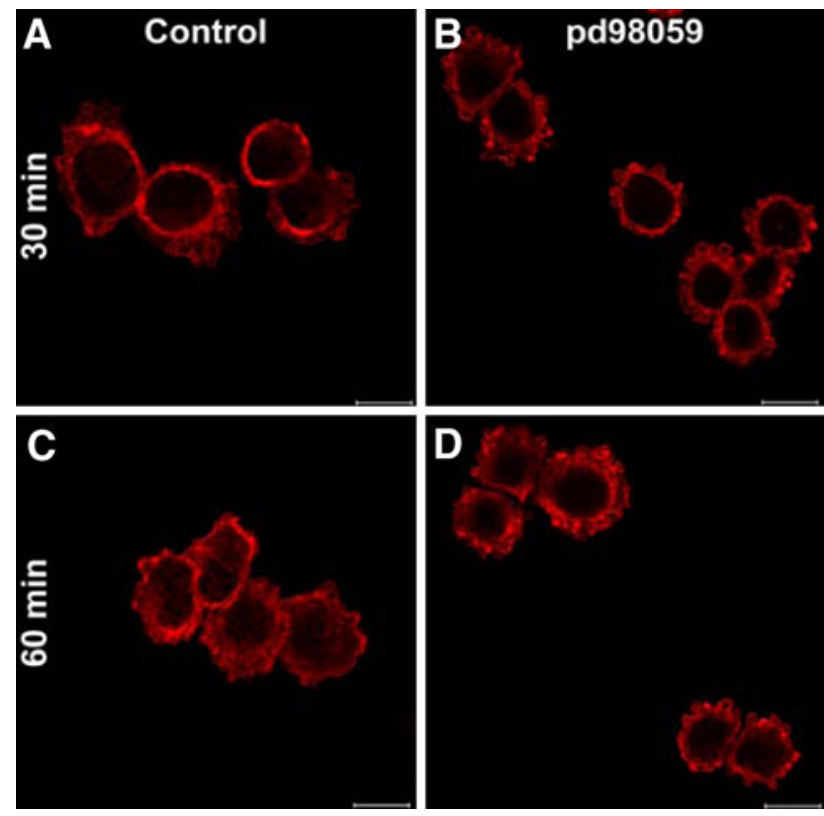

Fig. 9 Effect of inhibition of the MAPkinase pathway on membrane bleb formation. HeLa cells were synchronized, replated for 30 or $60 \mathrm{~min}$ as indicated and chemically fixed as described under "Materials and methods". Subsequently cells were labelled for F-actin (red) as described above. The MEK1 and MEK2 inhibitor pd98059 was added immediately after mitotic shake-off. In the presence of MEK1 and MEK2 inhibitor pd98059 (b, d), blebs of the membrane are present comparable to non-treated cells $(\mathbf{a}, \mathbf{c})$. Bar represents $10 \mu \mathrm{m}$

was reported during early stages of cell spreading. SICs were described to contain focal adhesion markers, to be enclosed by an F-actin sheath and were suggested to be precursors of focal adhesions (de Hoog et al. 2004).

Interestingly, the blebs of the membrane increased in size only when in contact with the substratum. This further indicates a role for integrin signalling. Moreover, the blebs disappeared faster at the apical side of cells compared to the basal side of cells. The presence of membrane blebs at the apical side may be related to the required increase in membrane area. If cells spread, the surface volume ratio increases dramatically, and this can be achieved by membrane growth. During mitosis, cells were shown to change volume (Boucrot and Kirchhausen 2008) and the area of the plasma membrane is controlled (Boucrot and Kirchhausen 2007). In this respect, it is of particular interest that the membrane blebs contain phosphorylated $\mathrm{CPLA}_{2} \alpha . \mathrm{cPLA}_{2} \alpha$ is usually activated by MAPK (van Rossum et al. 2001) and we demonstrate here that the membrane blebs indeed contain phosphorylated and consequently activated MAPK. Although a role of membrane blebs in cell attachment and signal transduction seems apparent, inhibition of both integrin-induced and MAPK-induced signaling has no effect on the formation of membrane blebs. Thus, it is tempting to suggest that the membrane blebs are required for membrane growth in order to allow cell spreading and in addition facilitate the spreading process to constitute sites of actin metabolism connected to integrin- and growth factor-induced signalling.

Alternatively, the restrictions of our cell culture conditions may mask the function of the blebs of the membrane that were observed. Membrane blebbing was related to cellular movement in rounded cells that lack mature focal adhesions and stress fibers (Friedl et al. 2001). It was described how blebs are generated during amoeboid migration in three-dimensional matrices (Charras 2008; Friedl et al. 2001; Friedl and Wolf 2010). In our experiments, cells were cultured in a two-dimensional environment. Hence, the blebs on the apical side of cells were not in contact with extracellular matrix. It will be interesting to see how the membrane blebs that are formed during early G1 behave when fully surrounded by extracellular matrix.

Acknowledgments This work is subsidized by the Dutch Space Organization (SRON, grant MG-059).

Open Access This article is distributed under the terms of the Creative Commons Attribution Noncommercial License which permits any noncommercial use, distribution, and reproduction in any medium, provided the original author(s) and source are credited.

\section{References}

Badley RA, Woods A, Carruthers L, Rees DA (1980) Cytoskeleton changes in fibroblast adhesion and detachment. J Cell Sci 43:379-390

Bohmer RM, Scharf E, Assoian RK (1996) Cytoskeletal integrity is required throughout the mitogen stimulation phase of the cell cycle and mediates the anchorage-dependent expression of cyclin D1. Mol Biol Cell 7:101-111

Boonstra J, Moes MJ (2005) Signal transduction and actin in the regulation of G1-phase progression. Crit Rev Eukaryot Gene Expr 15:255-276

Boonstra J, Mummery CL, Tertoolen LJG, van der Saag PT, de Laat SW (1981) Cation transport and growth regulation in neuroblastoma cells. Modulations of $\mathrm{K}^{+}$transport and electrical properties during the cell cycle. J Cell Physiol 107:75-83

Bottazzi MA, Buzzai M, Zhu X, Desdouets C, Brechot C, Assoian RK (2001) Distinct effects of mitogens and the actin cytoskeleton on CREB and pocket protein phosphorylation control the extent and timing of cyclin A promoter activity. Mol Cell Biol 21:7607-7616

Boucrot E, Kirchhausen T (2007) Endosomal recycling controls plasma membrane area during mitosis. Proc Natl Acad Sci USA 104:7939-7944

Boucrot E, Kirchhausen T (2008) Mammalian cells change volume during mitosis. PLoS One 3:e1477

Charras GT (2008) A short history of blebbing. J Microsc 231:466-478

de Hoog CL, Foster LJ, Mann M (2004) RNA and RNA binding proteins participate in early stages of cell spreading through spreading initiation centers. Cell 117:649-662

den Hartigh JC, van Bergen en Henegouwen PMP, Verkleij AJ, Boonstra J (1992) The EGF receptor is an actin-binding protein. J Cell Biol 119:349-355 
Diakonova M, Payrastre B, van Velzen AG, Hage WJ, Bergen en Henegouwen PMP, Boonstra J, Cremers AFM, Humbel BM (1995) Epidermal growth factor induces rapid and transient association of phospholipase C- $\gamma 1$ with EGF-receptor and filamentous actin at membrane ruffles of A431 cells. J Cell Sci 108:2499-2509

Fasshauer M, Iwig M, Glaesser D (1998) Synthesis of proto-oncogene proteins and cyclins depends on intact microfilaments. Eur J Cell Biol 77:188-195

Friedl P, Borgmann S, Bröcker EB (2001) Amoeboid leukocyte crawling through extracellular matrix: lessons from the Dictyostelium paradigm of cell movement. J Leukoc Biol 70:491-509

Friedl P, Wolf K (2010) Plasticity of cell migration: a multiscale tuning model. J Cell Biol 188:11-19

Grewal S, Morrison EE, Ponnambalam S, Walker JH (2002) Nuclear localisation of cytosolic phospholipase A2-alpha in the EA.hy.926 human endothelial cell line is proliferation dependent and modulated by phosphorylation. J Cell Sci 115:4533-4543

Heng Y-W, Koh C-G (2010) Actin cytoskeleton dynamics and the cell division cycle. Int J Biochem Cell Biol 42:1622-1633

Herbert SP, Ponnambalan S, Walker JH (2005) Cytosolic phospholipase A2-alpha mediates endothelial cell proliferation and is inactivated by association with the Golgi apparatus. Mol Biol Cell 16:3800-3809

Herbert SP, Odell AF, Ponnambalam S, Walker JH (2007) The confluence-dependent interaction of cytosolic phospholipase A2-alpha with annexin A1 regulates endothelial cell prostaglandin E2 generation. J Biol Chem. 282:34468-34478

Huang S, Chen CS, Ingber DE (1998) Control of cyclin D1, p27 (Kip1), and cell cycle progression in human capillary endothelial cells by cell shape and cytoskeletal tension. Mol Biol Cell 9:3179-3193

Huang S, Ingber DE (2002) A discrete cell cycle checkpoint in late G1 that is cytoskeleton-dependent and MAP kinase (ERK)independent. Exp Cell Res 275:255-264

Hulleman E, Bijvelt JJ, Verkleij AJ, Verrips CT, Boonstra J (1999a) Nuclear translocation of mitogen-activated protein kinase p42MAPK during the ongoing cell cycle. J Cell Physiol 180: 325-333

Hulleman E, Bijvelt JJ, Verkleij AJ, Verrips CT, Boonstra J (1999b) Integrin signaling at the M/G1 transition induces expression of cyclin E. Exp Cell Res 253:422-431

Iwig M, Czeslick E, Muller A, Gruner M, Spindler M, Glaesser D (1995) Growth regulation by cell shape alteration and organization of the cytoskeleton. Eur J Cell Biol 67:145-157
Lohez OD, Reynaud C, Borel F, Andreassen PR, Margolis RL (2003) Arrest of mammalian fibroblasts in $\mathrm{G} 1$ in response to actin inhibition is dependent on retinoblastoma pocket proteins but not on p53. J Cell Biol 161:67-77

Maness PF, Walsh RC (1982) Dihydrocytochalasin B disorganizes actin cytoarchitecture and inhibits initiation of DNA synthesis in 3T3 cells. Cell 30:253-262

Margadant C, van Opstal A, Boonstra J (2007) Focal adhesion signaling and actin stress fibers are dispensable for progression through the ongoing cell cycle. J Cell Sci 120:66-76

Moes M, Boonstra J, Regan-Klapisz E (2010) Novel role of $\mathrm{CPLA}_{2} \alpha$ in membrane and actin dynamics. Cell Mol Life Sci 67: $1547-1557$

Ohta T, Takasuka T, Ishibashi S, Ide T (1985) Cytochalasin D inhibits the progression from the $\mathrm{G} 0$ to $\mathrm{S}$ phase at the mid-prereplicative stage in Gc-7 cells stimulated with serum. Cell Struct Funct 10:37-46

Payrastre B, Bergen en Henegouwen PMP, Breton M, den Hartigh JC, Plantavid M, Verkleij AJ, Boonstra J (1991) Phosphoinositide kinase, diacylglycerol kinase, and phospholipase $\mathrm{C}$ activities associated to the cytoskeleton: effect of epidermal growth factor. J Cell Biol 115:121-128

Reshetnikova G, Barkan R, Popov B, Nikolsky N, Chang LS (2000) Disruption of the actin cytoskeleton leads to inhibition of mitogen-induced cyclin E expression, cdk2 phosphorylation, and nuclear accumulation of the retinoblastoma protein-related p107 protein. Exp Cell Res 259:35-53

Schaller MD (1996) The focal adhesion kinase. J Endocrinol 150:1-7

Schaller MD (2010) Cellular functions of FAK kinases: insight into molecular mechanisms and novel functions. J Cell Sci 123: $1007-1013$

Takasuka T, Ishibashi S, Ide T (1987) Expression of cell cycledependent genes in serum stimulated cells whose entry into $\mathrm{S}$ phase is blocked by cytochalasin D. Biochim Biophys Acta 909:161-164

Tsakiridis T, Bergman A, Somwar R, Taha C, Aktories K, Cruz TF, Klip A, Downey GP (1998) Actin filaments facilitate insulin activation of the src and collagen homologous/mitogen activated protein kinase pathway leading to DNA synthesis and c-fos expression. J Biol Chem 273:28322-28331

van Rossum GSAT, Klooster R, van den Bosch H, Verkleij AJ, Boonstra J (2001) Phosphorylation of p42/44MAPK by various signal transduction pathways activates phospholipase A2 to variable degrees. J Biol Chem 276:28976-28983 